\title{
OBSERVATIONS IN CONTROLLING HELICOBACTER PYLORI BETWEEN TRIPLE REGIME AND SEQUENTIAL REGIME
}

\author{
NOREEN AZAM ${ }^{1}$, MUHAMMAD TAHIR SHAH ${ }^{2}$, ADIL MEHRAJ $^{3}$, \\ MUHAMMAD ILYAS ${ }^{4}$, MANSOOR AHMAD ${ }^{3}$ \\ ${ }^{I}$ Department of Medicine, Military Hospital, Rawalpindi, ${ }^{2}$ Department of ENT, PAC (Pakistan Aeronautical Complex) \\ Hospital Kamra, Attock, ${ }^{3}$ Department of Anesthesia, PAC (Pakistan Aeronautical Complex) Hospital Kamra Attock, \\ ${ }^{4}$ Department of ENT, Postgraduate Medical Institute/Ameer ud Din Medical College/ Lahore General hospital, Lahore.
}

\begin{abstract}
Objective: To compare conventional triple regime and sequential regime in controlling of Helicobacter Pylori.

Methods: The study was conducted at Medical OPD Military Hospital, Rawalpindi for six months. The consecutive (nonprobability sampling) technique was used. All patients fulfilling inclusion criteria and diagnosed according to operational definition of Helicobacter Pylori infection were selected. All the information was entered, assessed and results were obtained through SPSS.

Results: According to our study the cases mean age was 36.23 \pm 10.87 years, ratio between male, female was 1.07:1. Overall efficacy achieved in 289 (67.21\%) patients (124 in set A and 165 in set B). So according to results sequential therapy has got much higher results as compared to triple therapy group.

Conclusion: It has been proved in our study that the sequential regime has got significantly better results than conventional triple regime in the management of Helicobacter Pylori eradication
\end{abstract}

Keywords: H. pylori, Eradication, observations.

How to cite this article: Azam N, Shah MT, Mehraj A, Ilyas M, Ahmad M. Observations in controlling helicobacter pylori between triple regime and sequential regime. Pak Postgrad Med J 2020;31(3): 155-158

This is an Open Access article distributed under the terms of the Creative Commons Attribution License (http://creativecommons.org/licenses/by/3.0), which permits unrestricted use, distribution, and reproduction in any medium, provided the original work is properly cited.

DOI: http://doi.org/10.51642/ppmj.v31i03.382

Correspondence to: Muhammad Tahir Shah, Department of ENT, PAC (Pakistan Aeronautical Complex) Hospital Kamra, Attock, Pakistan.

Email:227tahirshah@gmail.com

\section{INTRODUCTION}

Helicobacter Pylori is spiral, gram negative bacteria with many flagella for mobility. Its prevalence in the world is more than $50 \%$ and is much higher in developing countries ${ }^{1} .81 \%$ of adult population is infected with it in Pakistan ${ }^{2}$.

It is associated with different diseases including peptic ulcer formation, atrophic gastritis, dyspepsia, gastric cancer and gastric lymphoma. Early control is required for prevention of these diseases and their complications ${ }^{3}$. Triple regime in the most widely used therapy in Helicobacter pylori infection control. But its efficacy has reduced by the time below $80 \%$ due to drug resistance which is unacceptable ${ }^{3,4}$. So to overcome the resistance and to improve the results, sequential regimen was introduced with $98 \%$ eradication rate ${ }^{5}$. The target of this trial was to see the effectiveness of sequential and triple therapy in Helicobacter Pylori infection amongst local population as till date no such study is conducted in local population. This study may enable us to choose better eradication regimen for this highly prevalent pathogen.

Helicobacter pylori (H. pylori): Australian scientists Barry Marshall and Robin Warren discovered it in 1982 in patients of chronic gastritis and gastric ulcers. So it was also thought that it led to the development of duodenal ulcers and related diseases. But most of the human beings having it are asymptomatic and perhaps it may be the part of natural stomach ecology. ${ }^{6}$ It is present in the gastrointestinal tract of more than $50 \%$ of world population and is more common in underdeveloped 
countries. It has been suggested that it has developed power to attack the lining of stomach mucosa. ${ }^{7-8}$

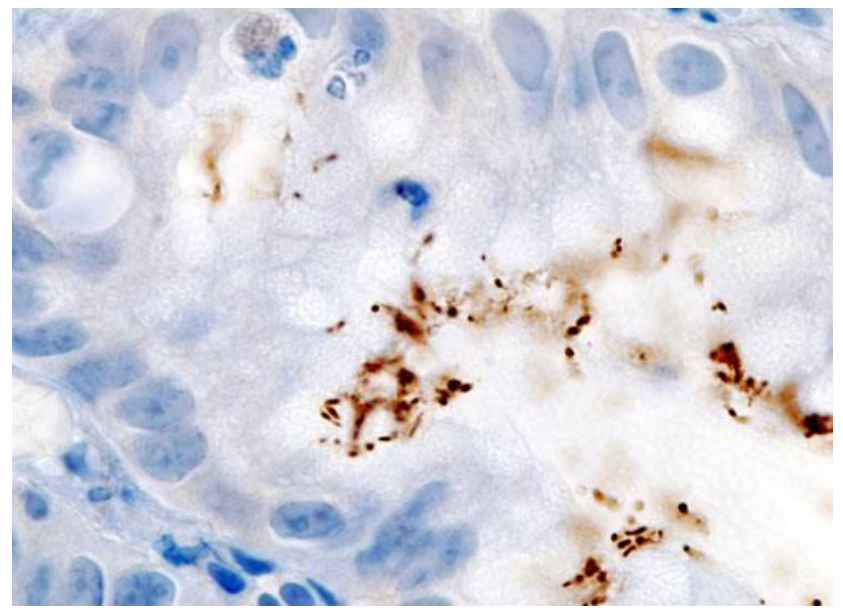

\section{Helicobacter pylori in stomach mucosa ${ }^{8}$}

oral--oral and feco--oral are its commonest ways of spread, Parents and siblings play a primary role in its transmission 9 . Infection has shown accumulation of neutrophils, mast cell, lymphocytes in gastric mucosa and is supposed to cause dysplastic and metaplastic alterations. Its gastric mucosal attachment has resulted in lowering the levels of cells glutathione, which is required for the mucosal repair and in immunity. It may lead to the production of autoantibodies with further increase in parietal cells atrophy ${ }^{10 .}$

Signs and symptoms of $\mathbf{H}$. pylori: Patients usually have no symptoms incase present these are due to acute gastritis like abdominal pain or nausea ${ }^{11,12}$. In case of chronic gastritis symptoms can be pain in stomach, feeling of nausea, vomiting and rarely dark stool. ${ }^{13}$ Its patients are in $20 \%$ risk of peptic ulcer and $1-2 \%$ risk of gastric cancer. ${ }^{14,15}$

Hypothesis: Sequential regime is better than triple regime.

\section{Operational Definitions}

\section{Helicobacter pylori infection}

Positive H. Pylori stool antigen in symptomatic patients having dyspepsia. Helicobacter pylori stool antigen was detected via immunochromatography monoclonal antibodies method.

Efficacy: In this study the efficacy was eradication of infection by sequential regime and triple regime in 4 weeks' time having stool antigen negative to H. pylori.

\section{Triple therapy}

Amoxicillin $1 \mathrm{gm} 2$ times daily 10 days

Clarithromycin $500 \mathrm{mg} 2$ times daily 10 days

Omeprazole $20 \mathrm{mg} 2$ times daily 10 days

\section{Sequential therapy}

Amoxicillin $1 \mathrm{gm} 2$ times daily 5 days

Omeprazole $20 \mathrm{mg} 2$ times daily 5 days

\section{Followed by}

Clarithromycin $500 \mathrm{mg} 2$ times daily 5 days

Metronidazole $400 \mathrm{mg} 2$ times daily 5 days

Omeprazole $20 \mathrm{mg} 2$ times daily 5 days

\section{METHODS:}

It was randomized control trial study conducted at Medical OPD Military Hospital, Rawalpindi. Its duration was 6 months

According to WHO guidelines, following are calculations for sample size:

- Level of significance is equal to $5 \%$.

- Power of test is equal to $80 \%$.

- Anticipated population in set ' $\mathrm{A}$ ' is equal to $85.9 \%$.

- Anticipated population in set ' $\mathrm{B}$ ' is equal to $75 \%$

- 215 patients sample size in each group (total 430 patients)

Consecutive (nonprobability sampling).

Inclusion criteria: Patients presenting with dyspepsia with positive Helicobacter Pylori stool antigen.

- Age 18-55 years.

- Both genders.

\section{Exclusion criteria:}

- Patients who had received Proton Pump Inhibitors/H2 receptor blockers or antibiotics in last two weeks.

- Patients who have received Helicobacter pylori eradication therapy previously.

- Patients having contraindications to drugs used in this study.

After approval of hospital research and ethical committee, all patients diagnosed according to operational definition, selected and distributed in 2 sets, set A was provided with triple eradication therapy and set B sequential Helicobacter pylori eradication therapy. Randomization of patients to either treatment group was done through lottery method. All patients were undergone detailed history, clinical examination, baseline investigations. $\mathrm{H}$ pylori stool antigen was done from AFIP Rawalpindi at time of inclusion and four weeks after completion of therapy. The objectives of study were 
declared to patients and written consent for participation was obtained. Patient's information was recorded in a Performa.

Data was assessed through SPSS. Efficacy was stratified among age and gender. Chi square test was applied to compare efficacy in both groups. Post stratification chi square test was applied keeping $\mathrm{p} \leq 0.05$ to be considered important.

\section{RESULTS}

Out of about 430 patients highest age found was 55 years, lowest was 18 years and mean was $36.23 \pm 10.87$.

Study mean value of age in set A was $35.84 \pm 10.97$ years while mean value in set B patients was $36.62 \pm 10.79$ years. In this study male cases were $223(51.86 \%)$ and female cases were 207(48.14\%). Ratio between male and female, found was 1.07:1. According to our study total number of male cases were 223 (111 in set $A$ and 112 in set B). Total number of female cases were 207(104 in set A and 103 in set B). Similarly, good results of treatment were found in 289 patients (124 in set A and 165 in set $B)$. Negative results of treatment were found in 141 individuals (91 in set A and 50 in set B).

So the efficacy showed in 289 patients (124 in set A and 165 in set B) and it did not show in 141 patients (91 in set $A$ and 50 in set B). Efficacy showed in 134 patients in less than 35 years of age (59 in set A and 75 in set B). Efficacy above 35 years is shown in 155 patients $(65$ in set $\mathrm{A}$ and 90 in set $\mathrm{B})$. Table 1

According to the study good results obtained in 157 male patients (69 in set $A$ and 88 in set $B$ ) and in female cases good results obtained in 132 patients (55 in set A and 77 in set B). Table 2

Chi value $=17.73$ Value of $p=0$

Table 1: Efficacy by age within study sets

\begin{tabular}{|c|c|c|c|c|c|}
\hline \multirow{2}{*}{$\begin{array}{c}\text { Age } \\
\text { (years) }\end{array}$} & \multirow{2}{*}{ Efficacy } & \multicolumn{2}{|c|}{ Study sets } & \multirow{2}{*}{ Total } & \multirow{2}{*}{$\begin{array}{c}\text { Value } \\
\text { of } p\end{array}$} \\
\hline & & Set A & Set $B$ & & \\
\hline \multirow{2}{*}{$<35$} & $\mathrm{Y}$ & 59 & 75 & 1 & \multirow[b]{2}{*}{0.} \\
\hline & & 52 & 23 & 75 & \\
\hline \multirow{2}{*}{$\geq 35$} & & 65 & 90 & 155 & \multirow{2}{*}{0.019} \\
\hline & No & 39 & 27 & 66 & \\
\hline
\end{tabular}

Table 2: Efficacy according to gender within study sets

\begin{tabular}{|c|c|c|c|c|c|}
\hline \multirow{2}{*}{ Gender } & \multirow{2}{*}{ Effica } & \multicolumn{2}{|c|}{ Study sets } & \multirow{2}{*}{ otal } & \multirow{2}{*}{$\begin{array}{c}\text { Value } \\
\text { of } p\end{array}$} \\
\hline & & Set A & Set $B$ & & \\
\hline \multirow{2}{*}{ Іа } & & 69 & 00 & & \multirow{2}{*}{0.007} \\
\hline & & 42 & 24 & & \\
\hline \multirow{2}{*}{ Fema } & & 55 & 77 & 13 & \multirow{2}{*}{0.001} \\
\hline & No & 49 & 26 & 75 & \\
\hline
\end{tabular}

\section{DISCUSSION}

This study was conducted at Medical OPD MH Rawalpindi. Managing $\mathrm{H}$. pylori infection is still a headache for physicians because no current drug therapy has been successful to control it in all infected individuals. Old triple therapy was advised as first-line therapy previously ${ }^{16}$ Then the sequential therapy was introduced and its efficacy was compared with triple regimes. Different comparative studies were conducted and it was found that results were better for sequential regime. ${ }^{17-18}$ In our study the efficacy was achieved in $289(67.21 \%)$ patients (124 patients from set A, Triple therapy and 165 from set B, Sequential therapy). So results proved that sequential regime is significantly more efficacious to triple regime and value of $\mathrm{p}=0.000$. Now few studies are mentioned below some are in favor of while others are against our results.

In a study by Jun-Won infection control rate was $75.9 \%$ for sequential regime group and $58.7 \%$ for the conventional triple regime group. Study showed that resistance was $18.2 \%$ for clarithromycin and $41.9 \%$ for metronidazole. ${ }^{19}$

In another study of 71 patients, $45(63.4 \%)$ patients received 10-day conventional triple regime on the other hand $26(36.6 \%)$ patients were given 10-day sequential regime. Later it was found out that despite of no gross difference in clinical scenario, sequential therapy showed much better controlling rate $84.6 \%$ against triple regime $48.8 \%$ (value of $\mathrm{p}=0.02$, odds ratio 0.19 ). ${ }^{20}$ In recently different studies that were carried out in Korea, sequential therapy had a better control rate against triple regime. ${ }^{21-22}$ Regarding making a choice as a first line management option in controlling $\mathrm{H}$. pylori sequential regime has shown much better results. Also, a large number of data was analyzed and sequential regimen was shown to have better control than either of the seven-days and ten-days triple regimes, with a control rate of $93.7 \%$, $75.9 \%$ and $79.6 \%$, respectively. ${ }^{23-24}$ It was found that Such strains of $\mathrm{H}$. pylori that are resistant to clarithromycin, Sequential therapy was found better in controlling them and the efficacy was $83.9 \%$ and for triple regime it was $35.1 \%$, respectively. ${ }^{25}$

\section{CONCLUSION}

So, our study proves that the sequential therapy is better than conventional triple therapy in the management of Helicobacter Pylori.

\section{ETHICAL APPROVAL}

The study was approved by the Ethical Review Committee of Military Hospital, Rawalpindi, dated September, 2020. 


\section{REFERENCES}

1. Yang JC, Lu CW, Lin CJ. Treatment of Helicobacter pylori infection: current status and future concepts. World journal of gastroenterology: WJG. 2014;20 (18):5283-5293.

2. Rasheed F, Ahmad T, Bilal R. Frequency of Helicobacter pylori infection using 13C-UBT in asymptomatic individuals of Barakaho, Islamabad, Pakistan. J Coll Physicians Surg Pak. 2011;21(6):379-381.

3. Malfertheiner P, Megraud F, O'Morain CA, Atherton J, Axon AT, Bazzoli F, et al. Management of Helicobacter pylori infection - the Maastricht IV/Florence consensus report. Gut. 2012;61(5):646-664.

4. De Francesco V, Giorgio F, Hassan C, Manes G, Vannella L, Panella C, et al. Worldwide H. pylori antibiotic resistance: a systematic. J Gastrointestin Liver Dis. 2010;19(4):409-414.

5. Kim Y S, Kim S J, Yoon J H, Suk K T, Kim J B, Kim J D. Randomized clinical trial: the efficacy of 10 day sequential therapy vs. a 14 day standard PPI-based triple therapy for Helicobacter pylori in Korea. . Aliment Pharmacol Ther 2011;34:1098-1105.

6. Blaser MJ. Who are we? Indigenous microbes and the ecology of human diseases. EMBO reports. 2006; 7(10):956.

7. Yamaoka Y. Helicobacter pylori: molecular genetics and cellular biology: Horizon Scientific Press; 2008.

8. Brown LM. Helicobacter pylori: epidemiology and routes of transmission. Epidemiologic reviews. 1999;22(2):283-297.

9. Luigi Santacroce. Helicobacter Pylori Infection. 2015 [cited 2016]; Available from: http://emedicine. medscape.com/article/176938-overview.

10. Lowenthal AC, Hill M, Sycuro LK, Mehmood K, Salama NR, Ottemann KM. Functional analysis of the Helicobacter pylori flagellar switch proteins. Journal of bacteriology. 2009;191(23):7147-7156.

11. Bytzer P, Dahlerup JF, Eriksen JR, Jarbøl D, Rosenstock S, Wildt S. Diagnosis and treatment of Helicobacter pylori in-fection. Dan Med Bull. 2011;58(4):C4271.

12. Butcher GP. Gastroenterology: an illustrated colour text: Elsevier Health Sciences; 2003.

13. Ryan KJ, Sherris JC. Sherris medical microbiology: An introduction to infectious diseases: McGraw-Hill Medical Publishing; 1994.

14. Chang AH, Parsonnet J. Role of bacteria in oncogenesis. Clinical microbiology reviews. 2010; 23(4):837-857.

15. Suerbaum S, Michetti P. Helicobacter pylori infection. New England Journal of Medicine. 2002; 347(15):1175-1186.
16. Malfertheiner P, Megraud F, O’Morain C, Bazzoli F, El-Omar E, Graham D, et al. Current concepts in the management of Helicobacter pylori infection: the Maastricht III Consensus Report. Gut. 2007;56(6):772-781.

17. Marshall B. Sequential therapy for Helicobacter pylori: a worthwhile effort for your patients. Annals of internal medicine. 2008;148(12):962-963.

18. Moayyedi P. Sequential regimens for Helicobacter pylori eradication. The Lancet. 2007;370(9592): 1010-1012.

19. Chung JW, Jung YK, Kim YJ, Kwon KA, Kim JH, Lee JJ, et al. Ten-day sequential versus triple therapy for Helicobacter pylori eradication: A prospective, open-label, randomized trial. Journal of gastroenterology and hepatology. 2012;27(11):1675-1680.

20. Laving A, Kamenwa R, Sayed S, Kimang'a AN, Revathi G. Effectiveness of sequential v. standard triple therapy for treatment of Helicobacter pylori infection in children in Nairobi, Kenya. SAMJ: South African Medical Journal. 2013;103(12):921-924.

21. Park H, Jung M, Jung J, Kwon J, Kim E, Seo H, et al. Randomised clinical trial: comparative study of 10-day sequential therapy with 7-day standard triple therapy for Helicobacter pylori infection in naïve patients. Alimentary pharmacology \& therapeutics. 2012;35(1):56-65.

22. Choi WH, Park DI, Oh SJ, Baek YH, Hong CH, Hong EJ, et al. [Effectiveness of 10 day-sequential therapy for Helicobacter pylori eradication in Korea]. The Korean journal of gastroenterology- Taehan Sohwagi Hakhoe chi. 2008;51(5):280-284.

23. Zullo A, De Francesco V, Hassan C, Morini S, Vaira D. The sequential therapy regimen for Helicobacter pylori eradication: a pooled-data analysis. Gut. 2007;56(10):1353-1357.

24. Gatta L, Vakil N, Leandro G, Di Mario F, Vaira D. Sequential therapy or triple therapy for Helicobacter pylori infection: systematic review and meta-analysis of randomized controlled trials in adults and children. The American journal of gastroenterology. 2009;104(12):3069-3079.

25. Gatta L, Di Mario F, Zullo A, Vaira D. Errors in a meta-analysis of treatments for Helicobacter pylori infection. Annals of internal medicine. 2008;149 (9):686;

\section{AUTHOR'S CONTRIBUTIONS:}

NA: Concept and Design

MTS: Manuscript writing:

AM, MA: Critical Analysis

MI: Guidance in preparing of manuscript 